\title{
NUMERICAL MODELLING OF THERMO-HYDRO- MECHANICAL (THM) IN DEFORMING POROUS MEDIA FOR SUBSURFACE SYSTEMS
}

\author{
NORHAN ABD. RAHMAN ${ }^{1}$, SAMIRA ALBATI KAMARUDDIN ${ }^{2}$ \& BERNHARD \\ A. SCHREFLER ${ }^{3}$
}

\begin{abstract}
The study of multiphase flow and heat flow in partially saturated porous media is important in environmental geomechanics engineering because of its relevance to consolidation of porous media in unsaturated zone. A numerical model which describes the thermo-hydro-mechanical (THM) coupled problems in deformable porous material with two-phase flow has been developed. The relationships between capillary pressure, saturation of water and relative permeabilities of water and gas, proposed by Brooks and Corey was used. An extended study of the numerical model, based on the COMES-GEO code was conducted recently to solve unsaturated problems in local condition of Kg. Puteh wellfield, Kota Bharu. This site is a potential shallow aquifer which contribute to the largest groundwater supply in Kota Bharu, Kelantan. Some numerical investigation on the proposed formulation is discussed with illustrative example problems to demonstrate solution procedures and validating of the model.
\end{abstract}

Key words: Multiphase flow; heat flow; deforming porous media; numerical model; unsaturated zone; thermo-hydro-mechanical.

\begin{abstract}
Abstrak. Kajian aliran berbilang-fasa dan aliran haba dalam bahantara berliang separa tepu menjadi semakin penting dalam kejuruteraan geomekanik persekitaran kerana ia berkait rapat dengan pengukuhan bahantara berliang itu di dalam zon tidak tepu. Satu model berangka telah dikembangkan untuk menghuraikan masalah terganding haba-hidro-mekanikal (THM) dalam bahan berliang boleh ubah bentuk dengan aliran dua-fasa. Hubungan yang disarankan oleh Brooks dan Corey telah digunakan kepada tekanan rerambut, ketepuan air dan kebolehtelapan air serta gas. Satu kajian lanjutan dibuat ke atas model berangka tersebut berasaskan kod COMES-GEO untuk menyelesaikan masalah yang berlaku dalam zon tak tepu di medan telaga Kg. Puteh, Kota Bharu, Kelantan iaitu sebuah akuifer cetek yang berpotensi untuk mengeluarkan bekalan air bumi terbanyak di daerah Kota Bharu. Untuk menunjukkan model dan prosedur penyelesaiannya, rumusan pelaksanaan berangka dan contoh-contoh masalah dibincangkan di dalam kajian ini.
\end{abstract}

Kata kunci: Aliran berbilang-fasa, aliran haba, bahan berliang boleh ubah bentuk, model berangka, zon tidak tepu, haba-hidro-mekanikal.

$1 \& 2$ Faculty of Civil Engineering, Universiti Teknologi Malaysia, 81310 Skudai, Johor Darul Takzim, Malaysia. Tel: 07-5503023, Fax: 07-5566157,e-mail: norhan@fka.utm.my; e-mail: amiera_din@hotmail.com

3 Department of Structural and Transportation Engineering, University of Padua, Via Marzolo 9, 35131 Padova, Italy. e-mail: bas@caronte.dic.unipd.it 


\subsection{INTRODUCTION}

In recent years there have been an increased interest in thermo-hydro-mechanics of partially saturated porous materials. Several mathematical models of transport processes were proposed in [1-5]. The studies on multiphase flow and heat flow in partially saturated porous media is significant in environmental geomechanics engineering because of its relevance to consolidation of porous media in unsaturated zone. The description of multiphase systems in porous media may be based either on the mixture theory integrated by the concept of volume fractions or on averaging theories and from a classical viewpoint on Biot's theory. For this study, the averaging theories developed by Hassanizadeh and Gray [6], based on spatial averaging operators were applied as it gives a better understanding on the microscopic situation and macroscopic relations. Recent studies by Chauteau and Dormieux [7] discussed the behaviour of unsaturated porous media in the light of a micromechanical approach based on the macroscopic and microscopic level.

The work described herein is a development of a numerical model for thermohydro-mechanical (THM) coupled problems in deformable porous material with two-phase flow. The model will be applied to the local condition of $\mathrm{Kg}$. Puteh wellfield, one of the major shallow aquifers contributing to the groundwater sources to Kota Bharu water supply demand. It is an extension of a study on the existing code known as the Computational Solid Mechanics (COMES-GEO) written by Baggio and Gawin, [8]. The code is developed along the lines of the theory outlined by Lewis and Schrefler [5] using finite element method. It is usually used in solving the problems of unsaturated zone of the subsurface systems. The primary function of the model is to provide prediction of future performance of selected site/situation. This includes the development of mathematical models to study the phenomena related to heat, and mass transfer in partially saturated deforming porous media.

\subsection{PHYSICAL MODEL}

The Biot's theory is derived and extended for the case of non-isothermal two-phase flow in deforming porous media. Schrefler, Zhan and Simoni [4, 9] made this extension for the case of slow phenomena. For isothermal case with the air phase at atmospheric pressure, inertia forces are considered, as done by Zienkiewicz et al., [1]. For simplicity, and dealing with macroscopic variables small displacements are assumed for the solid phase.

The void of the skeleton is partly filled with water and partly with moist air (dry air + water vapour) where the summation of the degree of water saturation, $S_{w}$ and degree of gas saturation, $S_{g}$ is equal to one, i.e.

$$
S_{w}+S_{g}=1
$$


Stress is defined as tension positive for solid phase and pore pressure is defined as compressive positive for fluids. The water pressure, $p^{\text {w }}$ and gas pressure, $p^{g}$ are related through the capillary pressure, $p^{c}: p^{g}-p^{w}=p^{c}$ where, $p^{c}$ is the function of $S_{w}$ and $T$ (temperature): $p^{c}=p^{c}\left(S_{w}, T\right)$. The constitutive law of the solid is introduced through the concept of effective stress, $\sigma^{\prime}=\sigma+\mathbf{I} p^{s}$, which stipulates that the main characteristics of the solid-phase constitutive relation can be written in terms of $\sigma^{\prime}$ (also known as Bishop stress) where $\sigma$ is the total stress tensor, $\mathbf{I}$ the second-order unit tensor and $p^{s}$ is the average pressure of both water and air surrounding the grains.

\subsection{MATHEMATICAL MODEL}

The model is based on strong physical background aimed at handling situations which span from fully saturated to almost dry conditions. It consists of balance equations of mass, linear momentum and energy, as well as appropriateness of the constitutive equations. The macroscopic balance equations applied in the model were obtained from balance equations at macroscopic level by use of spatial averaging operators. The gas phase is modelled as an ideal gas composed of dry air and water vapour, which are considered as two miscible species. Phase changes of water (evaporation-condensation) and heat transfer through conduction and convection, as well as latent heat transfer are considered. This model is an extension of the heat and mass transfer formulation to the case of deformable porous media by Baggio $e t$. al., [10], based on Whitaker's approach [11-12]. The model makes use of a modified effective stress concept together with the capillary pressure relationship. The selected primary variables are gas pressure, capillary pressure, temperature and displacements which correspond to the measured quantities in the laboratory. This is an important aspect when selecting the appropriate constitutive equations. The governing equations and discretized equations are solved by Newton-Raphson procedure.

\subsection{Conservation Equation}

Only slow phenomena and small displacements are considered in the following equations. The assumption is based on thermal equilibrium between solid matrix, gas and liquid, given the same temperature for the three constituents. The laws of continuum are used to formulate heat and mass transfer in porous media comprised of four equations which takes into consideration the mass of the dry air, mass of the water species (liquid water + vapour), enthalpy of the whole medium (latent heat) and linear momentum of the multiphase medium. The governing equations of the model, expressed in terms of the chosen state variables, gas pressure, $p_{g}$, capillary pressure, $p_{c}$, temperature, $T$ and displacements vector, $\mathbf{u}$, are stated as follows: 
(a) Dry air conservation equation:

$$
\begin{aligned}
\phi \frac{\partial}{\partial t}\left[(1-S) \rho_{g a}\right] & +(1-S) \rho_{g a} \frac{\partial \phi_{h y d r}}{\partial t}+\alpha(1-S) \rho_{g a} \frac{\partial}{\partial t}(\nabla . \mathbf{u})+\nabla \cdot\left(\rho_{g a} \mathbf{v}_{g}\right) \\
& +\nabla \cdot\left(\rho_{g} \mathbf{v}_{g a}^{d}\right)=0
\end{aligned}
$$

(b) Water species (liquid-vapour) conservation equation:

$$
\begin{aligned}
\phi \frac{\partial}{\partial t}\left[(1-S) \rho_{g w}\right] & +(1-S) \rho_{g w} \frac{\partial \phi_{h y d r}}{\partial t}+\alpha(1-S) \rho_{g w} \frac{\partial}{\partial t}(\nabla \cdot \mathbf{u})+\nabla \cdot\left(\rho_{g w} \mathbf{v}_{g}\right) \\
& +\nabla \cdot\left(\rho_{g} \mathbf{v}_{g w}^{d}\right)==-\phi \frac{\partial}{\partial t}\left(S \rho_{w}\right)-S \rho_{w} \frac{\partial \phi_{h y d r}}{\partial t} \\
& -\alpha S \rho_{w} \frac{\partial}{\partial t}(\nabla \cdot \mathbf{u})-\nabla \cdot\left(\rho_{g w} \mathbf{v}_{l}\right)-\frac{\partial}{\partial t}\left(\Delta \boldsymbol{m}_{h y d r}\right)
\end{aligned}
$$

(c) Energy conservation (enthalpy balance):

$$
\begin{aligned}
& \rho C_{p} \frac{\partial T}{\partial t}+\left[C_{p w} \rho_{w} \mathbf{v}_{l}+C_{p g} \rho_{g} \mathbf{v}_{g}\right] \nabla T-\nabla \cdot\left(\lambda_{e f f} \nabla T\right)= \\
& =\Delta h_{p h a s e}\left[\phi \frac{\partial}{\partial t}\left(S \rho_{w}\right)+S \rho_{w} \frac{\partial \phi_{h y d r}}{\partial t}+\alpha S \rho_{w} \frac{\partial}{\partial t}(\nabla \cdot \mathbf{u})+\nabla \cdot\left(\rho_{w} \mathbf{v}_{l}\right)\right] \\
& +\Delta h_{h y d r} \frac{\partial}{\partial t}\left(\Delta \boldsymbol{m}_{h y d r}\right)
\end{aligned}
$$

(d) Linear momentum balance equation for the whole mixture of terms of total stresses (in incremental form):-

$$
\nabla \cdot \frac{\partial \sigma}{\partial t}+\frac{\partial \rho}{\partial t} \mathbf{b}=0
$$

where $\rho$ is the averaged density of the multi-phase medium, given by

$$
\rho=(1-\phi) \rho_{s}+\phi S \rho_{l}+\phi(1-S) \rho_{g}
$$

and $\phi$ is the total porosity, $S$ is saturation of water, $\alpha$ is known as Biot's constant, $\sigma$ represents total stress tensor, $T$ is temperature, $\mathbf{u}$ means displacement vector of solid matrix, $\mathbf{b}$ indicates vector of the specific body term (normally corresponding to the acceleration of gravity) and $\nabla=\frac{\partial}{\partial x_{k}} \mathbf{i}_{k}$, Nabla operator, 
where $i_{k}$ is versor of the $x_{k}$ axis. Meanwhile $\mathbf{v}_{g}$ and $\mathbf{v}_{l}$ is the velocity of gaseous and liquid phase; $C_{p}, C_{p g}$ and $C_{p w}$ are effective specific heat of porous medium, specific heat of gas mixture and water; $\lambda_{e f f}$ is the effective thermal conductivity; $\phi_{h y d r}$ as part of porosity resulting from dehydration process; $\Delta m_{h y d r}$, mass source term related to hydration-dehydration process and finally $\Delta h_{\text {phase }}$ is the enthalpy balance of the phase per unit mass.

For fluid phases the multiphase Darcy's law has been applied as constitutive equation, thus for capillary water we have:

$$
\begin{array}{ll}
\mathbf{v}_{w}=-\frac{\mathbf{K} K_{r w}}{\mu_{w}}\left(\nabla p_{w}-\rho_{w} \mathbf{b}\right) & p_{c}<p_{b} \\
\mathbf{v}_{w}=-\frac{\mathbf{K} K_{r w}}{\mu_{w}}\left(\nabla p_{g}-\nabla p_{c}-\rho_{w} \mathbf{b}\right) & p_{c r}>p_{c} \geq p_{b} \\
\mathbf{v}_{w}=0 & p_{c} \geq p_{c r}
\end{array}
$$

while for the gas phase holds:

$$
\begin{array}{ll}
\mathbf{v}_{g}=-\frac{\mathbf{K} K_{r g}}{\mu_{g}} \nabla p_{g} & p_{c} \geq p_{b} \\
\mathbf{v}_{g}=0 & p_{c}<p_{b}
\end{array}
$$

where $\mathbf{K}$ is intrinsic permeability tensor, $K_{r g}$ and $K_{r w}$ are relative permeabilities of the gaseous and liquid phases, $\mathbf{v}_{w}$ and $\mathbf{v}_{g}$ are volume averaged velocities of capillary water and gaseous phase relative to the solid phase and $\mathbf{b}$ indicates the specific body force term. For the description of the diffusion process of the binary gas species mixture (dry air and water vapour) Fick's law is applied:

$$
\mathbf{v}_{g a}^{d}=-\frac{M_{a} M_{w}}{M_{g}^{2}} D_{e f f} \nabla\left(\frac{p_{g a}}{p_{g}}\right)=\frac{M_{a} M_{w}}{M_{g}^{2}} D_{e f f} \nabla\left(\frac{p_{g w}}{p_{g}}\right)=-\mathbf{v}_{g w}^{d}
$$

where $\frac{1}{M_{g}}=\frac{\rho_{g w}}{\rho_{g}} \frac{1}{M_{w}}+\frac{\rho_{g a}}{\rho_{g}} \frac{1}{M_{a}}$

and $D_{e f f}$ is the effective diffusion coefficient of vapour species in the porous medium, and $M_{a}, M_{g}$ and $M_{w}$ are the molar mass of dry air, gas moisture and water vapour. For all the gaseous constituents, i.e. dry air (ga), water vapour (gw) and moist air (g), the equation of state of perfect gases: $p_{g a}=\rho_{g a} T R / M_{a}, p_{g w}=\rho_{g w} T R / M_{w}$, $p_{g}=\rho_{g} T R / M_{g}$, and Dalton's law is $p_{g}=p_{g a}+p_{g w}$ are assumed as constitutive equations. 
The constitutive relationship for the solid skeleton is assumed in the form: $d \sigma^{\prime}=$ $K_{T}\left(d \varepsilon-d \varepsilon^{T}-d \varepsilon^{0}\right)$ together with the definition of the strain matrix B relating strain and displacement: $\varepsilon=\mathbf{B u}$, where $K_{T}$ is a tangent matrix and $d \varepsilon^{T}=\mathbf{I} \frac{\beta_{s}}{3} d T$ defined as the strain increment caused by thermo-elastic expansion, $\beta_{s}$ is the cubic thermal expansion coefficient of the solid and $d \varepsilon^{o}$ is the autogeneous strain increments.

\subsection{Initial and Boundary Conditions}

The initial conditions specify the full fields of gas pressure, capillary pressure, temperature and displacements:

$$
p_{g}=p_{g}^{o}, \quad p_{c}=p_{c}^{0}, \quad T=T^{0}, \quad \mathbf{u}=\mathbf{u}^{0} \quad \text { at } t=0
$$

The boundary conditions can be of the first kind or Dirichlet's boundary conditions on $\Gamma_{i}^{1}$ :

$$
p_{g}=\hat{p} \text { on } \Gamma_{g}^{1}, \quad p_{c}=\hat{p} \text { on } \Gamma_{c}^{1}, \quad T=\hat{T} \text { on } \Gamma_{T}^{1}, \quad \mathbf{u}=\mathbf{u} \text { on } \Gamma_{\mathbf{u}}^{1}
$$

of the second kind or Neumann's boundary conditions on $\Gamma_{i}^{2}$ :

$$
\begin{aligned}
-\left(\rho_{g a} \mathbf{v}_{a}-\rho_{g} \mathbf{v}_{g w}^{d}\right) \cdot \mathbf{n} & =q_{g a} & & \text { on } \Gamma_{g}^{2}, \\
-\left(\rho_{g w} \mathbf{v}_{g}+\rho_{w} \mathbf{v}_{l}+\rho_{g} \mathbf{v}_{g w}^{d}\right) \cdot \mathbf{n} & =q_{g w}+q_{l} & & \text { on } \Gamma_{c}^{2}, \\
-\left(\rho_{w} \mathbf{v}_{l} \Delta h_{\text {phase }}-\lambda_{e f f} \nabla T\right) . \mathbf{n} & =q_{T} & & \text { on } \Gamma_{T}^{2}, \\
\sigma \cdot \mathbf{n} & =q_{g a} & & \text { on } \Gamma_{\mathbf{u}}{ }^{2},
\end{aligned}
$$

and of the third kind or Cauchy's (mixed) boundary conditions on $\Gamma_{i}^{3}$ :

$$
\begin{array}{ll}
\left(\rho_{g w} \mathrm{v}_{g}+\rho_{w} \mathrm{v}_{l}+\rho_{g} \mathrm{v}^{d} g w\right) \cdot \mathbf{n}=\beta_{c}\left(\rho_{g w}-\rho_{g w \infty}\right) & \text { on } \Gamma_{c}^{3} \\
\left(\rho_{w} \mathrm{v}_{l} \Delta h_{\text {phase }}-\lambda_{e f f} \nabla T\right) \cdot \mathbf{n}=\alpha_{c}\left(T-T_{\infty}\right)+e \sigma_{o}\left(T^{4}-T_{\infty}{ }^{4}\right) & \text { on } \Gamma_{T}^{3},
\end{array}
$$

where the boundary $\Gamma=\Gamma_{i}^{1} \cup \Gamma_{i}^{2} \cup \Gamma_{i}^{3}, \mathbf{n}$ is the unit normal vector, for the surrounding gas, $q_{g a}, q_{g w}, q_{l}$ and $q_{T}$ corresponding to the imposed dry air flux, imposed vapour flux, imposed liquid flux and imposed heat flux.

$t$ is the imposed traction, $\rho_{g w_{\infty}}$ is the mass concentration of water vapour and too is the temperature in the far field of undisturbed gas phase, $e$ is the emmisivity of the interface, $\sigma_{o}$ is the Stefan-Boltzmann constant, while $\alpha_{c}$ and $\beta_{c}$ are convective heat and mass transfer coefficients. 


\subsection{NUMERICAL MODEL}

The Galerkin form of the method of weighted residuals (MWR) was selected to produce an integral representation of the basic conservation laws. Within each element, a set of nodal points is established at which the dependent variables Pg, Pc, T, ux and uy are evaluated. For the purpose of developing the equations of the nodal point unknowns, an individual element is discretised from the assemblage. Within each element, it is assumed that the dependent variables can be expressed in terms of approximating function (shape functions) by:

$$
\begin{array}{ll}
p_{g}=p_{g}(t)=\mathbf{N}_{p} \overline{\mathbf{p}}_{g}(t), & p_{c}=p_{c}(t)=\mathbf{N}_{p} \overline{\mathbf{p}}_{c}(t), \\
T=T(t)=\mathbf{N}_{t} \overline{\mathbf{T}}(t), & \mathbf{u}=\mathbf{u}(t)=\mathbf{N}_{u} \overline{\mathbf{u}}(t) .
\end{array}
$$

The integral or weak form of the heat and mass transfer equations (and others required to complete the model), was obtained by means of the Galerkin procedure (weighted residuals) and expressed in matrix form as follows:

$$
\begin{aligned}
& \mathbf{C}_{g g} \hat{\mathbf{p}}_{\mathrm{g}}+\mathbf{C}_{\mathrm{gc}} \hat{\mathbf{p}}_{\mathbf{c}}+\mathbf{C}_{\mathrm{gt}} \widehat{\mathbf{T}}+\mathbf{C}_{\mathrm{gu}} \hat{\mathbf{u}}+\mathbf{K}_{\mathrm{gg}} \overline{\mathbf{p}}_{\mathrm{g}}+\mathbf{K}_{\mathrm{gc}} \overline{\mathbf{p}}_{\mathbf{c}}+\mathbf{K}_{\mathrm{gt}} \overline{\mathbf{T}}+\mathbf{f}_{\mathrm{g}}=0, \infty \\
& \mathbf{C}_{\mathbf{c g}} \hat{\mathbf{p}}_{\mathbf{g}}+\mathbf{C}_{\mathbf{c c}} \hat{\mathbf{p}}_{\mathbf{c}}+\mathbf{C}_{\mathbf{c t}} \hat{\mathbf{T}}+\mathbf{C}_{\mathbf{c u}} \hat{\mathbf{u}}+\mathbf{K}_{\mathbf{c g}} \overline{\mathbf{p}}_{\mathbf{g}}+\mathbf{K}_{\mathbf{c c}} \overline{\mathbf{p}}_{\mathbf{c}}+\mathbf{K}_{\mathbf{c t}} \overline{\mathbf{T}}+\mathbf{f}_{\mathbf{c}}=\mathbf{0}, \\
& \mathbf{C}_{\mathbf{t g}} \hat{\mathbf{p}}_{\mathbf{g}}+\mathbf{C}_{\mathrm{tc}} \hat{\mathbf{p}}_{\mathbf{c}}+\mathbf{C}_{\mathrm{tt}} \widehat{\mathbf{T}}+\mathbf{C}_{\mathrm{tu}} \hat{\mathbf{u}}+\mathbf{K}_{\mathrm{tg}} \overline{\mathbf{p}}_{\mathbf{g}}+\mathbf{K}_{\mathrm{tc}} \overline{\mathbf{p}}_{\mathbf{c}}+\mathbf{K}_{\mathrm{tt}} \overline{\mathbf{T}}+\mathbf{f}_{\mathbf{t}}=\mathbf{0}, \\
& C_{u u} \hat{\mathbf{u}}+C_{u g} \hat{\mathbf{p}}_{\mathbf{g}}+\mathbf{C}_{\mathbf{u c}} \hat{\mathbf{p}}_{\mathbf{c}}+\mathbf{C}_{\mathbf{u t}} \widehat{\mathbf{T}}+\mathbf{f}_{\mathbf{u}}=\mathbf{0} \text {, }
\end{aligned}
$$

The above non-symmetric, non-linear and coupled system of ordinary differential equations can be written as: $\quad \mathbf{C}(\mathbf{x}) \dot{\mathbf{x}}+\mathbf{K}(\mathbf{x}) \mathbf{x}+\mathbf{f}(\mathbf{x})=\mathbf{0}$ where $\mathbf{x}^{\mathbf{T}}=\left\{\overline{\mathbf{p}}_{\mathbf{g}}, \overline{\mathbf{p}}_{\mathbf{c}}, \overline{\mathbf{T}}, \overline{\mathbf{u}}\right\}$ and the non-linear (matrix) coefficients $\mathbf{C}(\mathbf{x}), \mathbf{K}(\mathbf{x})$ and $\mathbf{f}(\mathbf{x})$ are obtained by assembling the sub-matrices indicated in (4.2).

\subsection{NUMERICAL EXAMPLES}

In this particular example, partially saturated flow in deforming porous media is investigated under the assumption that, either air remains at atmospheric pressure in the unsaturated zone, or there is flow of both water and air. For partially saturated conditions we have one for water and one for air. The equations for the saturationcapillary pressure and relative permeability-saturation relationships as was used by Liakopoulos [13] are valid for saturation $S \geq 0.91$ and have in the following form:

$$
\begin{aligned}
& S=1-1.9722 \times 10^{11} p_{c}^{2.4279} \\
& K_{r l}=1-2207(1-S)^{1.0121}
\end{aligned}
$$


The relative permeability of the gas phase was assumed to be as given by Brooks and Corey [14]:

$$
\begin{gathered}
K_{r g}=\left(1-S_{e}\right)^{2}\left(1-S_{e}^{5 / 3}\right) \\
S_{e}=(S-0.2) /(1-0.2)
\end{gathered}
$$

For numerical purposes, the examples were solved in one-dimensional, unsaturated, consolidation problem and compared with a previous solution by Lewis and Schrefler, [5]. The column of soil samples was simulated by 20 eight-node isoparametric finite elements of equal size and within 103 nodes as shown in Figure 5.1. At the beginning, and besides uniform flow conditions (i.e. unit vertical gradient of the potential and $p_{c}=0$ on the top surface), a mechanical equilibrium state was assumed. The boundary conditions used: for the lateral surface are: $q_{T}=0, u_{h}=0$, where $u_{h}$ is the horizontal displacement of the soil; for the top surface: $p_{g}=p_{a t m}$, where $p_{a t m}$ is the atmospheric pressure, $T=293.15 \mathrm{~K}$. For the bottom surface: $p_{g}=$ $p_{\text {atm }}, p_{c}=0$ for $t>0, T=293.15 \mathrm{~K}, u_{h}=u_{v}=0$, where $u_{v}$ is the vertical displacement soil.

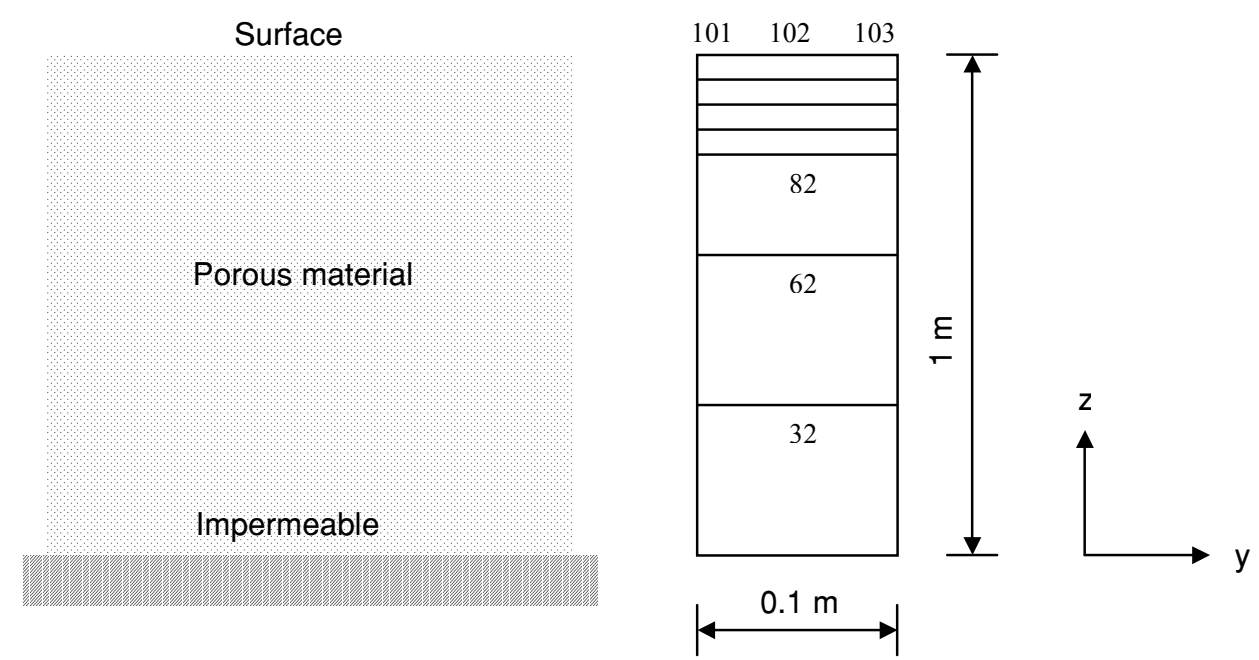

Figure 5.1 One-dimensional model and finite element mesh

The first problem example was simulated using two different values of intrinsic permeability, i.e. $K_{1}=8.63 \times 10^{-13} \mathrm{~m}^{2}$ and $K_{2}=9.37 \times 10^{-12} \mathrm{~m}^{2}$. These values represent the soil permeability for a selected study area at $\mathrm{Kg}$. Puteh wellfield. The porosity of the soil is estimated as 0.42 and whilst other parameters assumed as follows:

Young's modulus

Poisson's ratio

$$
\begin{aligned}
E & =1.3 \mathrm{MPa} \\
v & =0.4
\end{aligned}
$$


Solid grain density

Liquid density

Water viscosity

Air viscosity

Gravitational acceleration

Atmosphere pressure

Biot's constant

$$
\begin{aligned}
\rho^{s} & =2000 \mathrm{~kg} / \mathrm{m}^{3} \\
\rho^{w} & =1000 \mathrm{~kg} / \mathrm{m}^{3} \\
\mu^{w} & =1 \times 10^{-3} \mathrm{Pas} \\
\mu^{g} & =1.8 \times 10^{-5} \mathrm{Pas} \\
g & =9.806 \mathrm{~m} / \mathrm{s}^{2} \\
p_{\text {atm }} & =101325 \mathrm{~Pa} \\
\alpha & =1
\end{aligned}
$$

The illustration in Figure 5.2 and 5.3 show no great differences between the two results. Figure 5.2 display the results for $K_{1}=8.63 \times 10^{-13} \mathrm{~m}^{2}$ and porosity $=0.42$ which illustrates good agreement with previous experimental results of Liakopoulos for $K_{1}=4.5 \times 10^{-13} \mathrm{~m}^{2}$ and porosity $=0.2975$ as shown in Figure 5.4. There are some differences between the $K_{1}$ and $K_{2}$ results (Figure 5.2 and 5.3) for gas pressure, capillary pressure and saturation of water, although there are similarities as the pat-

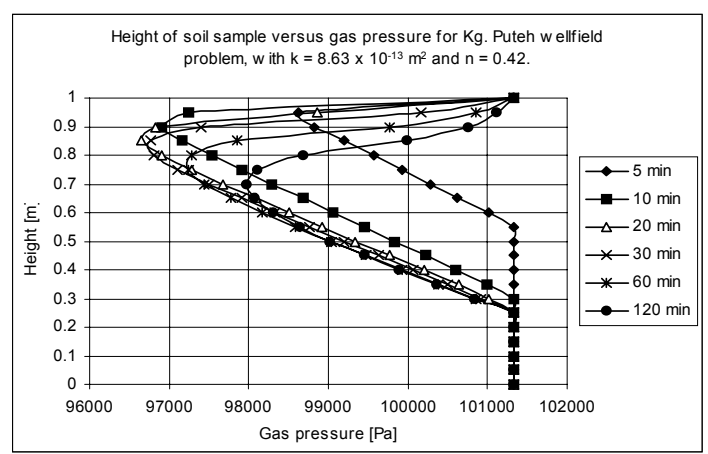

(a)

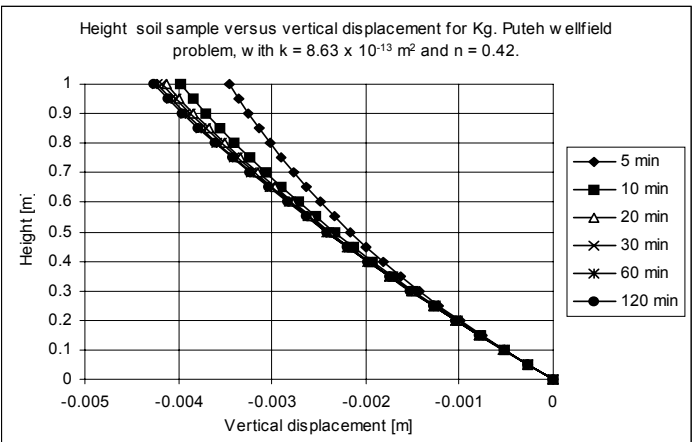

$(c)$

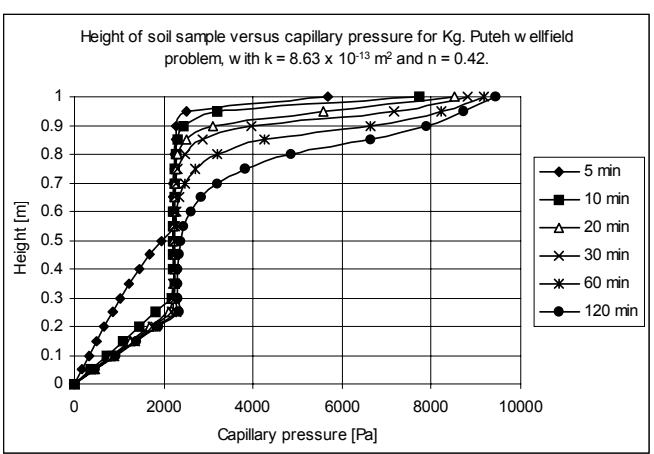

(b)

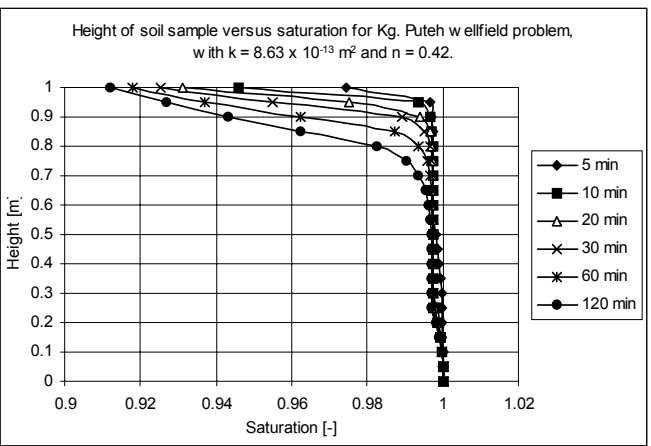

$(d)$ 


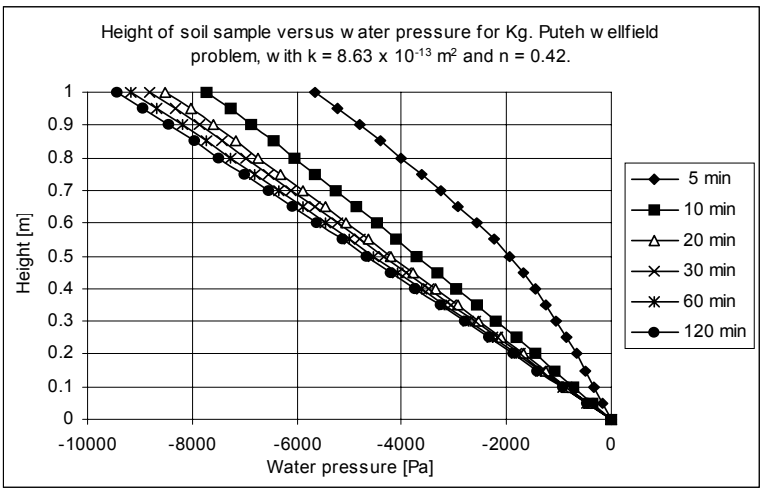

$(e)$

Figure 5.2 The resulting profiles of $(a)$ gas pressure, $(b)$ capillary pressure, $(c)$ vertical displacement, $(d)$ saturation and $(e)$ water pressure for unsaturated case with $K_{1}=8.63 \times 10^{-13} \mathrm{~m}^{2}$ and $n=0.42$

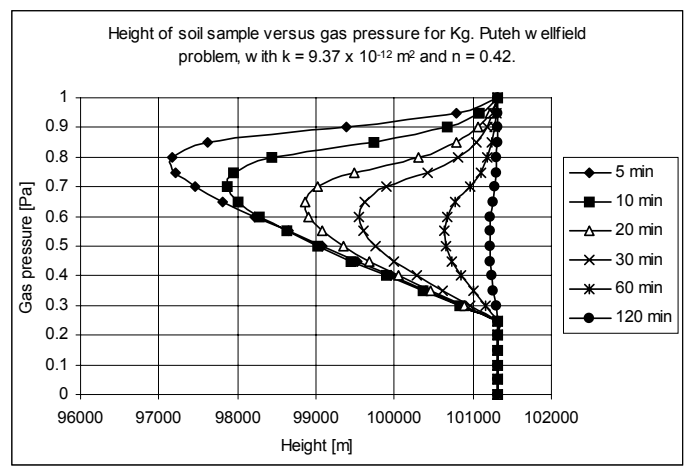

(a)

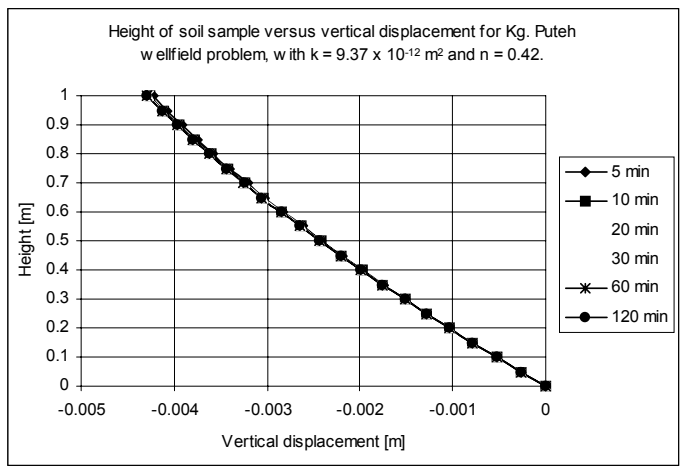

$(c)$

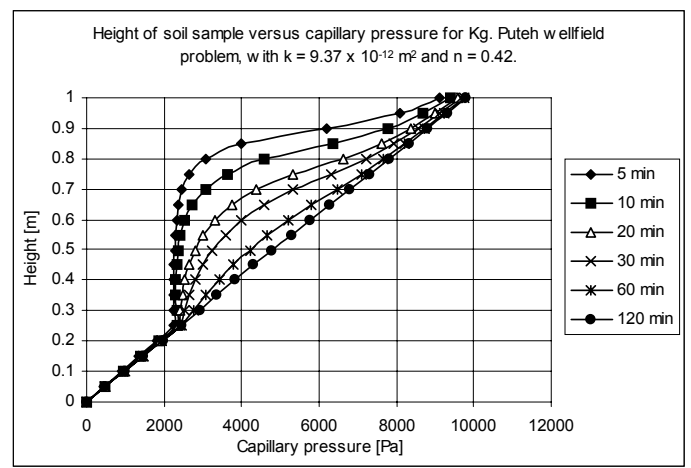

$(b)$

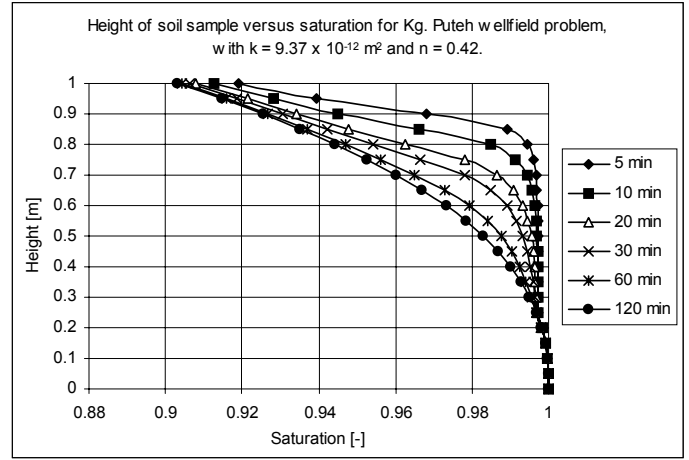

(d) 


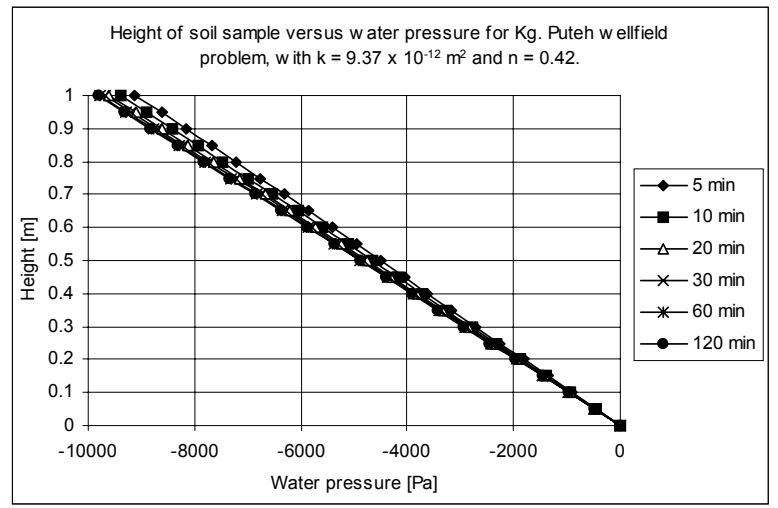

$(e)$

Figure 5.3 The resulting profiles of $(a)$ gas pressure, $(b)$ capillary pressure, $(c)$ vertical displacement, $(d)$ saturation and $(e)$ water pressure for unsaturated case with $K_{2}=9.37 \times 10^{-12} \mathrm{~m}^{2}$ and $n=0.42$

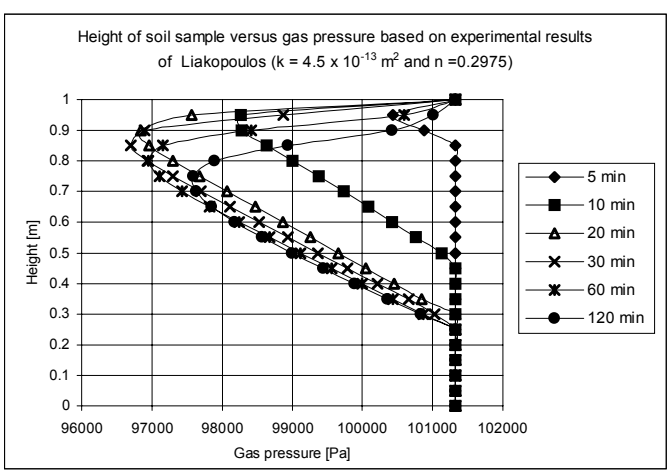

(a)

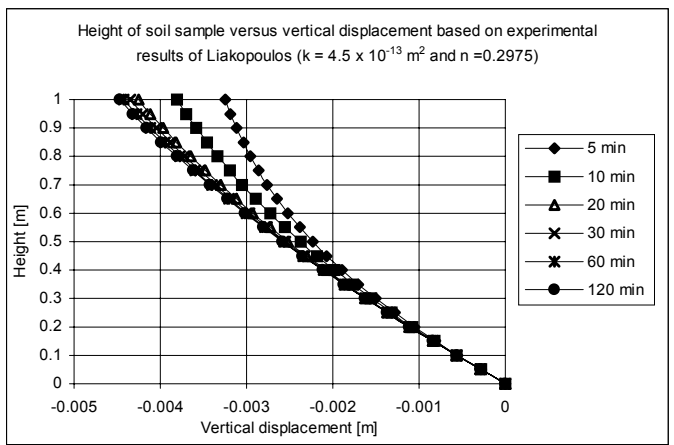

$(c)$

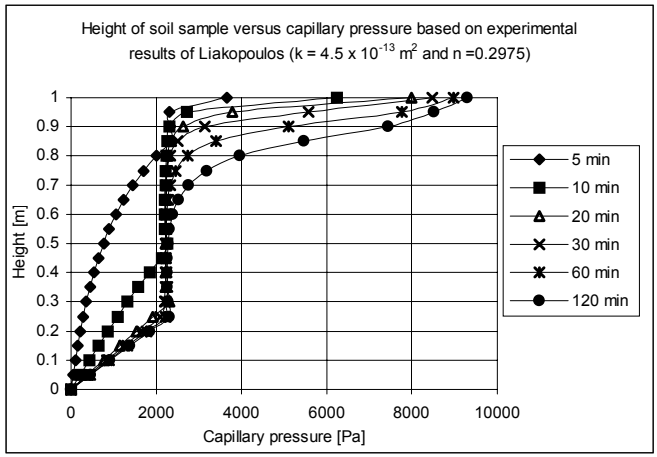

(b)

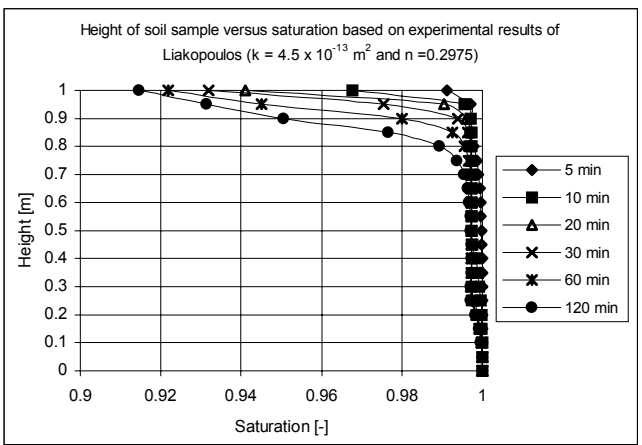

(d) 


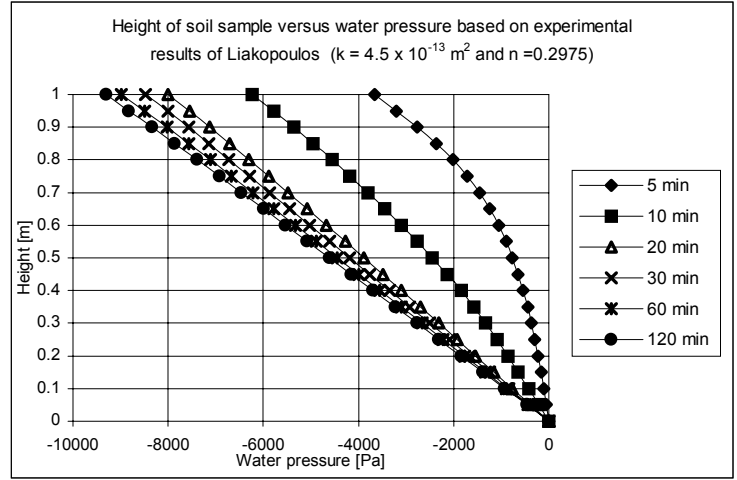

$(e)$

Figure 5.4 The resulting profiles of $(a)$ gas pressure, $(b)$ capillary pressure, $(c)$ vertical displacement, $(d)$ saturation and $(e)$ water pressure for unsaturated case with $K=4.5 \times 10^{-13} \mathrm{~m}^{2}$ and $n=0.2975$ based on experimental results of Liakopoulos

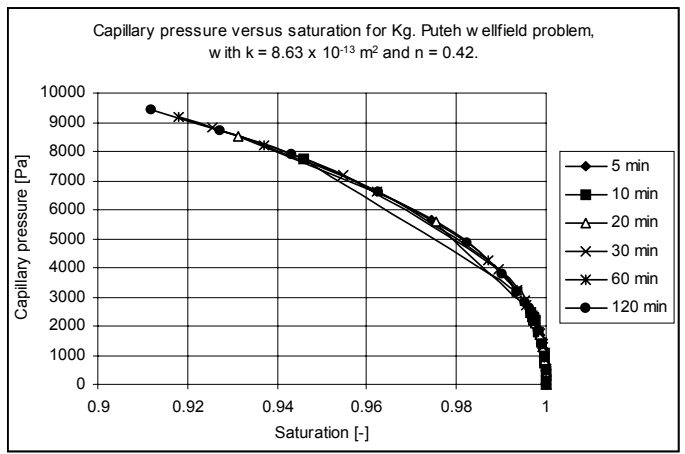

(a)

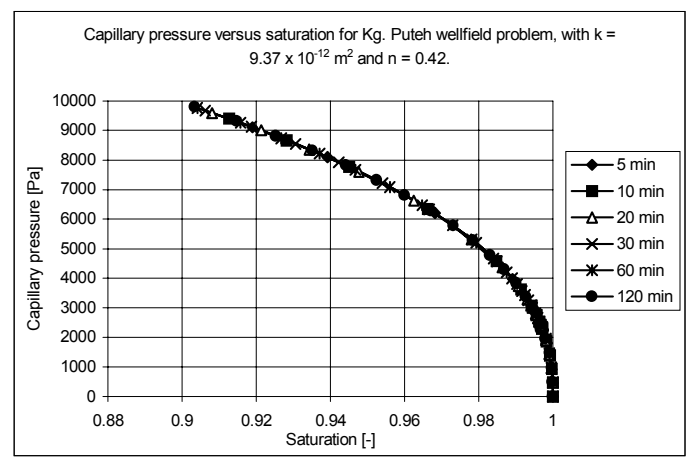

(b)

Figure 5.5 The resulting profiles of capillary pressure versus saturation of water for unsaturated case with (a) $K_{1}=8.63 \times 10^{-13} \mathrm{~m}^{2}$ and $n=0.42$ and (b) $K_{2}=9.37 \times 10^{-12} \mathrm{~m}^{2}$ and $n=$ 0.42

tern. Meanwhile Figure 5.5 shows the relationshi ps profiles of capillary pressure and saturation for $K_{1}$ and $K_{2}$. Both curves indicate the same patterns for selected absolute time. The capillary pressure decreased gradually until water saturation reaches zerto.

The profiles of vertical displacement are shown in Figure 5.6 (a) and (b). Two different sets of Young's modulus: $E_{1}=1.0 \times 10^{3} \mathrm{~Pa}$ and $E_{2}=1.0 \times 10^{9} \mathrm{~Pa}$ were selected to test the deformation of the material with respect to the average intrinsic permeability of $K_{1}$ and porosity $=0.42$. 


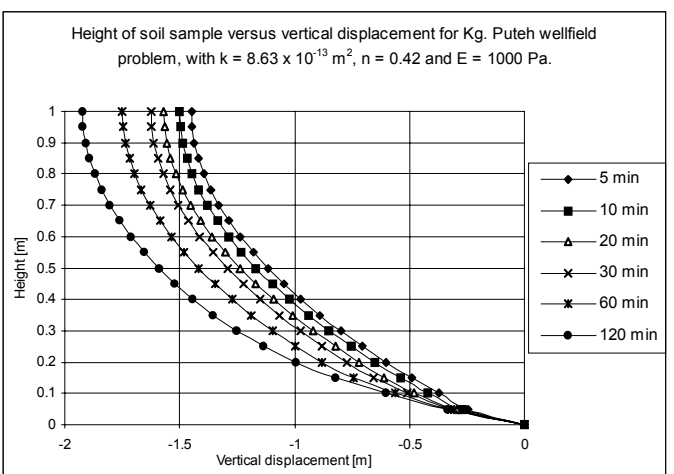

(a)

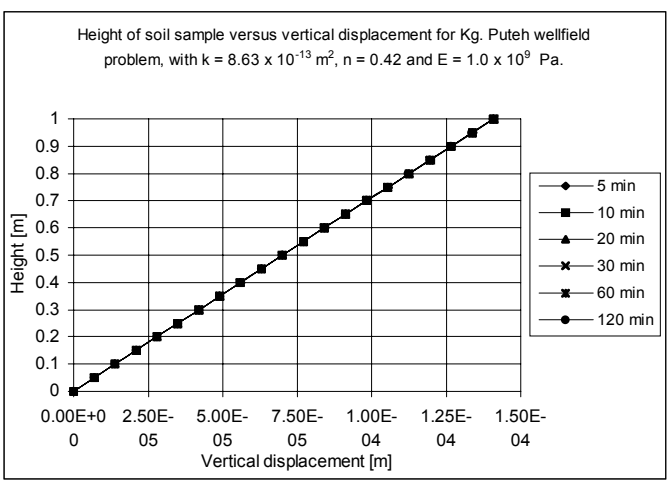

(b)

Figure 5.6: The resulting profiles of height of soil sample versus vertical displacement for $(a) K_{1}=$ $8.63 \times 10^{-13} \mathrm{~m}^{2}, n=0.42$ and $E_{1}=1000 \mathrm{~Pa}$ and $(b) K_{2}=8.63 \times 10^{-13} \mathrm{~m}^{2}, n=0.42$ and $E_{2}=1.0 \times 10^{9} \mathrm{~Pa}$

\subsection{CONCLUSIONS}

A fully coupled model for simulating heat and mass transfer in deformable porous materials involving phase changes phenomena (evaporation, condensation and latent heat transfer) has been presented. The model based on a strong physical background clearly identifies that the constitutive equations and other coefficients are needed to characterize the analyzed medium. The model results in a set of nonlinear and coupled partial differential equations. Which are discretized in space using finite element method and finite differences method to solve for the gas pressure, $p_{g}$, capillary pressure, $p_{c}$ temperature $T$ and displacements $u$ as primary variables. Due to the non-linearity of the equations a Newton-Raphson approach was used for solving the numerical problems. The validity of the approach was verified by agreement between the simulation results and experimental data of Liakopoulos, [13]. Further examples showed that the robustness of the model in dealing with various problems and the appreciable influences of proper physical modelling with regards to phase changes and realistic boundary conditions affects the evolution of the phenomena. The results indicate that the model can be generalised for many other problems on deforming porous media specifically those concerning thermohydro-mechanical in subsurface systems.

\section{REFERENCES}

[1] Zienkiewicz O. C., Y. M. Xie, B. A. Schrefler, A. Ledesma, N. Bicanic. 1990. Static and Dynamic Behaviour of Soils: A Rational Approach to Quantitative Solutions, II, Semi-saturated Problems. Proc. R. S. London. A 429: 311 - 321.

[2] Coussy O. 1991. Mecanique des Milieux Poreux. Paris: Editions Technip. 
[3] Abd. Rahman N. and R. W. Lewis. 1999. Finite Element Modelling of Multiphase Immiscible Flow in Deforming Porous Media for Subsurface Systems. Journal of Computers and Geotechnics. Elsevier Science. 24(1): $41-63$.

[4] Schrefler B. A., Zhan Xiaoyang, L. Simoni. 1995. A Coupled Model for Water Flow, Airflow and Heat Flow in Deformable Porous Media. Int. J. Num. Meth. Heat Fluid Flow. 5: 531 - 547.

[5] Lewis R. W. and B. A. Schrefler. 1998. The Finite Element Method in the Static and Dynamic Deformation and Consolidation of Porous Media. New York: John Wiley.

[6] Hassanizadeh M. and W. G. Gray. 1979. General Conservation Equations for Multiphase Systems: 2. Mass, Momenta, Energy and Entropy Equations. Adv. Water Res. 2: $191-203$.

[7] Chateau X. and L. Dormieux. 2000. The Behaviour of Unsaturated Porous Media in the Light of a Micromechanical Approach. Proceeding of the Asian Conference on Unsaturated Soils Unsat-Asia 2000/ Singapore. Rotterdam: A. A. Belkema.

[8] Schrefler B. A. 1999. COMES GEO. Part I: Theoretical Manual \& Part II: User Guide. University of Padua, Italy.

[9] Schrefler B. A. and Zhan Xiaoyang. 1993. A Fully Coupled Model for Water Flow and Airflow in Deformable Porous Media. Water Resources Research. 29: 155 - 67.

[10] Baggio P., C. Bonacina, and M. Strada. 1993. Trasporto di calore e di massa nel calcestruzzo celulare. $L a$ Termotecnica. 45(12): $53-60$.

[11] Whitaker S. 1977. Simultaneous Heat, Mass and Momentum Transfer in Porous Media: A Theory of Drying. Advances in Heat Transfer. 13. Academic, New York.

[12] Whitaker S. 1980. Heat and Mass Transfer in Granular Porous Media. Advances in Drying. 1. Hemisphere, New York.

[13] Liakopoulos A. C. 1965. Transient Flow Through Unsaturated Porous Media. Ph. D. Thesis. University of California, Berkeley.

[14] Brooks R. N. and A.T. Corey. 1966. Properties of Porous Media Affecting Fluid Flow. J. Irrig. Drain. Div. Am. Soc. Civ. Eng. 92(IR2): $61-68$. 